\title{
A Constituição dos Estados Unidos, Separação de Poderes e Poder Regulamentador
}

\author{
DÉBORA MARA CORREA DE AZEVEDO \\ Possui graduação em Direito pela Pontifícia Universidade Católica do Rio Grande do Sul (1996) \\ Pós-Graduação em Direito do Estado pela UFRGS. Atuou como advogada de 1997 a 2008. \\ Atualmente exerce atividades na UFRGS (PPG-Agronegócios), na qualidade de servidora es- \\ tatutária.
}

Submissão: 17.10 .2013

Decisão Editorial: 16.01.2013

RESUMO: Muitos estudos sobre a Constituição dos Estados Unidos têm sido realizados no sentido de tentar explicar a sua longevidade e vigência. Sabe-se que, desde o final do século XVIII, ela exerce uma profunda influência sobre os modelos institucionais da democracia ocidental, e, como é de conhecimento de todos, permanece soberana e viva até os dias de hoje3. Entretanto, existem entendimentos no sentido de que a solidez desse documento possa estar abalada, seja no tocante a modificações exigíveis a todas as Constituições por conta da evolução social, situação econômica e administrativa de cada nação; seja em razão das demandas impostas aos governos para o próprio desenvolvimento do País. Estudos existem também no sentido de que a longevidade da Constituição estadunidense não teria perdurado por tanto tempo, e que, implicitamente, mudanças objetivas ocorreram nesses mais de 200 anos de existência. Tais mudanças objetivas seriam decorrência de alterações interpretativas que atribuíram sentidos diversos ao texto constitucional, e, por conseguinte, essas mudanças de compreensão teriam gerado novos direitos. Nesse diapasão foram travados, nos dias atuais, alguns debates entre constitucionalistas americanos acerca da possível necessidade de alteração da Constituição norte-americana. Destaca-se, nesse caso, uma possível nova divisão de poderes. Adiante, observar-se-á, em especial, o entendimento do Professor Bruce Ackerman, do Professor Neal Kumar Katyal, do também Professor Christopher Yoo e do Constitucionalista americano Laurence Tribe, que tratam, entre outros assuntos, acerca da divisão de poderes e do poder regulamentador das agências reguladoras nos Estados Unidos. Diante desse estudo, é possível concluir que, de fato, as alterações interpretativas da Constituição estadunidense foram tantas e tão grandes, podendo-se afirmar que a Carta não permaneceu intacta durante os mais de 200 anos de sua existência. No tocante à doutrina da nova divisão de poderes, verifica-se que há um debate acerca do assunto, sendo que alguns se mostram favoráveis à criação de agências reguladoras como um quarto poder, ou mesmo dentro do Poder Executivo, e outros, ainda, são contrários a essa teoria.

PALAVRAS-CHAVE: Constituição norte-americana; nova separação de poderes; agências reguladoras.

ABSTRACT: Many studies on the U.S. Constitution have been made trying to explain its longevity and effectiveness. It is known that since the late eighteenth century it exerts a deep influence on Western

1 Sugestão de publicação: Revista Direito Público (ISSN 1806-8200). 
institutional models of democracy, and as everybody knows, it remains sovereign and live up to the present. However, there are opinions that the solidity of that document may be shaken, either as to changes demandable to all Constitutions due to social evolution and the economical and administrative situation of each nation, or because of the demands imposed to governments for the development of the country. Also, there are studies affirming that the longevity of the U.S. Constitution would not have lasted so long, and that, implicitly, objective changes have occurred over 200 years of existence. Such objective changes would be due to interpretative alterations which had attributed different meanings to the constitutional text, and, therefore, those changes of understanding would have generated new rights. Currently, some discussions have occurred among the Constitutionalists about the possible necessity of changing the U.S. Constitution. It's noteworthy, a possible new division of powers. Further, it will be observed, in particular, the understanding of Professor Bruce Ackerman, Professor Neal Kumar Katyal, and Professor Christopher Yoo, as well as the American constitutionalist Laurence Tribe who, among other things, deal with the division of powers and the regulatory power of the regulatory agencies in the United States. Thus, it is possible to conclude that interpretative changes of U.S. Constitution were so many and so large that it can be affirmed that the Constitution has not remained intact for over the 200 years of its existence. As to the new doctrine of division of powers, it is verified that there is a debate about the subject and some are favorable to the creation of regulatory agencies as a fourth Power, or even within the Executive Power, and others are against this theory.

KEYWORDS: U.S. Constitution; the new separation of powers; regulatory agencies.

SUMÁRIO: Introdução; 10 surgimento da Constituição Norte-Americana; 2 Bill of rigths e garantia dos direitos naturais; 3 Um novo olhar acerca da solidez e imutabilidade da Constituição Norte-Americana; 40 caso Plessy v. Ferguson; 5 A Corte de Warren; 6 Da divisão de poderes; 70 sistema de checks and balances; 80 poder regulador; 90 Administrative Procedure Act (Lei de Procedimento Administrativo) e as agências reguladoras; 10 Discussão acerca da competência sobre as agências; 11 Das Modernas Doutrinas da Separação de Poderes; 11.1 Bruce Ackerman; 11.20 entendimento do Professor Neal Kumar Katyal; 11.3 Pode o diálogo entre agências servir como a nova separação de poderes? (Professor Christopher S. Yoo); 11.4 Laurence Tribe; Conclusão; Referências.

\section{INTRODUÇÃO}

O debate acerca dos fundamentos sobre os quais se assenta a Constituição norte-americana sempre existiu, mas a razão do poder efetivo desse documento até hoje enseja discussões entre os mais renomados constitucionalistas. Interessante é notar que se trata, a Carta Constitucional, de um documento que possui somente sete artigos; e tão somente 27 emendas foram editadas desde a sua criação (1789), sendo que o presente estudo se propõe a analisar o entendimento de modernos doutrinadores acerca de mudanças propostas no sistema de divisão de poderes da constituição estadunidense.

\section{SURGIMENTO DA CONSTITUIÇÃO NORTE-AMERICANA}

Importa, por primeiro, relembrar o momento histórico em que a Constituição norte-americana foi promulgada. 
Sabe-se que no final do século XVIII as então colônias inglesas norte-americanas se desenvolviam com certa autonomia da coroa inglesa, sendo que o consequente descontentamento com o parlamento inglês decorrente da forte arrecadação imposta aos colonos, a desorganização administrativa da Inglaterra decorrente das constantes trocas de Primeiro Ministro efetuadas pelo Rei George II, entre outros fatores, culminaram com o processo de independência das treze colônias.

Nessa mesma época, as publicações de Russeau, Voltaire e Locke o qual idealizou pela primeira vez o Princípio da Separação dos Poderes apareciam na Europa e, por consequência, passaram a influenciar também a elite colonial da América do Norte. Enfim, o iluminismo francês florescia na América e influenciava sobremaneira também os idealizadores da primeira e única Constituição americana.

Sendo a primeira Constituição escrita no mundo, foi elaborada pelos representantes de nove das treze colônias que formavam a nacionalidade das colônias inglesas, corporificando o raciocínio filosófico do século XVIII. Na sua formação prevaleceu a ideia de conceder à nacionalidade americana, já independente, uma Carta de Princípios que fortalecesse a nacionalidade, e consequentemente a liberdade, a prosperidade e a democracia. Os Fundadores da Constituição norte-americana, todos formados no iluminismo e no protestantismo, fizeram dela um modelo do racionalismo da época².

O debate original que cercou a criação da Constituição em 1787-1788 formou-se entre os federalistas e os antifederalistas. Os primeiros, partidários e criadores da carta, argumentavam que a Constituição era o cumprimento, e não repúdio, da Revolução, e oferecia um governo inteiramente republicano e popular. Nesse sentido são as palavras de Martin Diamond: "Com a Constituição os norte-americanos completaram a meia-revolução iniciada em 1776 e tornaram-se o primeiro povo moderno a enfrentar plenamente a questão da democracia" ${ }^{\prime \prime}$.

Em contrapartida, os oponentes denunciavam que a Constituição era uma negação dos princípios de 1776 (Estatuto da Confederação) e um documento aristocrático para criar um governo antidemocrático. Nesse passo, cumpre salientar que permanece até hoje o entendimento de alguns estudiosos no sentido de que a Constituição é antidemocrática, e que se destinou a proteger os ricos frustrando as maiorias populares ${ }^{4}$.

Enfim, democrática ou não, o entendimento predominante é o de que a Constituição permanece até hoje incólume e soberana. Nesse sentido, pode-se

2 SCANTIMBURgo, João de. Prefácio. In: PADOVER, Saul K. A constituição viva dos Estados Unidos. São Paulo: IBRASA, 1987. p. 160.

3 GOLDWIN, Robert A; SCHAMBRA, William A. Constituição norte-americana. Rio de janeiro: Forense, 1986. p. 190.

4 Idem, ibidem 
afirmar que certamente nenhum dos líderes revolucionários da época da independência poderia prever a possibilidade da ascensão, sobre toda a América, de um governo nacional tão forte e tão amplo quanto o que a Constituição ofereceu.

Alguns atribuem o fato de tratar-se, o futuro país que veio a ser chamado Estados Unidos da América, na época, de uma terra sem passado, sem história, que acolheu homens para nela começarem uma vida nova, e que foi preponderante para o estabelecimento de instituições duradouras, bem como para inaugurarem uma república presidencial. Os Fundadores restauraram a ideia da República, deram-Ihe conteúdo político e acrescentaram-lhe o que nunca antes lhe fora possível, a eleição de um Presidente com mandato a prazo determinado ${ }^{5}$.

\section{BILL OF RIGTHSE GARANTIA DOS DIREITOS NATURAIS}

Importa referir que, após a conclusão do texto constitucional, para aquietar as severas críticas e lograr a ratificação do documento, os defensores da constituição prometeram uma Declaração de Direitos destinada a proteger os cidadãos contra o governo. Assim, no primeiro Congresso introduziu-se uma série de emendas, das quais as dez primeiras passaram a ser conhecidas como Declaração de Direitos (Bill of Rights) contendo garantias estritas e permanentes contra as indevidas e ilegais intromissões governamentais na vida do indivíduo. A Declaração de Direitos entrou em vigor em novembro de 1791, e é considerada por seus defensores um dos feitos mais nobres e sólidos da democracia norte-americana.

A ratificação ocorreu entre dezembro de 1787 e maio de 1790, sendo que Rhode Island foi o último Estado a promover a ratificação ${ }^{6}$.

A Constituição, portanto, confunde-se com o próprio ato de fundação dos Estados Unidos, mas vale dizer que ela não se limita a organizar instituições políticas do país. Inspirada também pelas ideias da escola de direito natural e recorrendo à ideia de contrato social, fixa solenemente os limites dos poderes reconhecidos às autoridades federais nas suas relações com o Estado e com os cidadãos. Tais limites foram especialmente determinados pelas dez primeiras emendas ${ }^{7}$.

A Constituição dos Estados Unidos garantiu também, após as Emendas nos 13, 14 e 15, votadas no período da Guerra Civil, que alguns direito naturais não serão violados ou postos em xeque pelas autoridades dos Estados.

SCANTIMBURGO, João de. Prefácio. In: PADOVER, Saul K. Op. cit., p. 160.

PADOVER, Saul K. A constituição viva dos Estados Unidos. São Paulo: IBRASA, 1987. p. 27-28.

DAVID, Renè. Os grandes sistemas de direito contemporâneo. São Paulo: Martins Fontes, 2002. p. 494. 
Cumpre referir, finalmente, que o texto constitucional deixa perceber que na formação da Carta Constitucional houve uma preocupação com a rigidez formal e a flexibilidade material do documento, o que está claramente demonstrado na sua parte inicial quando trata da separação de poderes, não sendo admitidas interferências recíprocas nem a transferência de poderes, nem parcial, nem temporal ${ }^{8}$.

\section{UM NOVO OLHAR ACERCA DA SOLIDEZ E IMUTABILIDADE DA CONSTITUIÇÃO NORTE-AMERICANA}

De igual forma, importa ressaltar os entendimentos contrários que se revelam com o aprofundamento dos estudos acerca dessa renomada Constituição. No artigo "O constitucionalismo norte-americano e sua contribuição para a compreensão contemporânea da Constituição", o Professor Doutor José Luiz Quadro de Magalhães, da PUCMG e UFMG, refere que

sobre a Constituição norte-americana muito tem se falado, por isso muitos são também os equívocos. Primeiro diz-se que os Estados Unidos tiveram apenas uma Constituição, mas esta não parece ser a compreensão de seus intérpretes e estudiosos. Alguns autores afirmam encontrar-se nos Estados Unidos da América ao menos três Constituições, outros falam em sete Constituições diferentes. Isso significa que, embora desde 1787 o texto com sete artigos permaneça em vigor com 27 emendas, ocorreram modificações interpretativas que atribuíram sentidos diversos aos significantes do seu texto, e essas mudanças de compreensão geraram novos direitos.

Para compreender o que foi dito, é importante lembrar que Constituição não é texto. O texto é um sistema de significantes aos quais atribuímos significados. Nesse sentido, toda leitura de um texto significa atribuição de sentidos e atribuição de sentidos significa atribuir valores, que mudam quando mudam os valores sociais. A sociedade muda por meio das contradições e conflitos internos e externos. Logo, quando muda a sociedade, mudam os valores, logo, mudam os conceitos das palavras (significantes), aos quais, portanto, passamos atribuir novos significados.

O processo evolutivo da Constituição dos Estados Unidos da América ocorre, principalmente, por meio das suas mutações interpretativas, decorrentes da evolução de valores de uma sociedade em permanente conflito. ${ }^{9}$

Dessa forma, verifica-se uma nova forma de interpretação da Constituição de 1789. Compartilham do mesmo entendimento do Professor Magalhães renomados constitucionalistas, conforme adiante se observará.

Idem, ibidem

MAGALHÃES, José Luiz Quadros de. O constitucionalismo norte-americano e sua contribuição para a compreensão contemporânea da Constituição. Jus Navigandi, Teresina, n. 452, out. 2004. Disponível em: <http://jus.com.br/revista/texto/5769>. Acesso em: 18 dez. 2012. 
Interessante é notar o entendimento de Jorge Miranda quanto à necessidade de modificações constitucionais em âmbito geral:

Se as Constituições na sua grande maioria se pretendem definitivas no sentido de voltadas para o futuro, sem duração prefixada, nenhuma Constituição que vigore por um período mais ou menos longo deixa de sofrer modificações - para se adaptar às circunstâncias e a novos tempos ou para acorrer a exigências de solução de problemas que podem nascer até da sua própria aplicação.

A modificação das Constituições é um fenômeno inelutável da vida jurídica, imposta pela tensão com a realidade constitucional e pela necessidade de efetividade que as tem de marcar, mais do que modificáveis, as Constituições são modificadas. Ou, doutro prisma (na senda de certa doutrina): nenhuma Constituição se esgota num momento único - o da sua criação; enquanto dura, qualquer constituição resolve-se num processo - o da sua aplicação - no qual intervêm todas as participantes na vida Constitucional. ${ }^{10}$

Calha referir, ainda, o posicionamento do Professor José Luiz Quadro de Magalhães, quando refere que o principal motivo da existência de poucas mudanças formais do texto, por meio de emendas, é o fato de que esse texto sintético e principiológico permite mutações interpretativas, mudança de compreensão de seu sentido e do conceito de seus princípios, que torna desnecessário o recurso constante da mudança do texto, pois muda-se a Constituição mudando o seu sentido, a sua compreensão, sem ter que mudar o texto.

No tocante à limitação de interpretação constitucional, o Professor ressalta que a mudança interpretativa tem limites, impostos pelo próprio texto. Logo, um texto sintético, que contenha mais princípios do que regras, permite maiores mudanças interpretativas do que um texto analítico, com excesso de regras, que travem a mudanças de compreensão dos princípios. Quanto mais detalhado o texto, quanto mais regras, menor o espaço para as mudanças interpretativas. Segundo ele, pode-se dizer que mesmo um texto detalhado, minucioso, também muda de sentido, embora o espaço da mudança seja menor.

Conclui, aduzindo que, ao contrário do que se diz, de que a Constituição dos EUA é uma pequena, o seu texto sintético permite construções interpretativas muito amplas, fazendo com que a constituição dos EUA, juntamente com a Inglesa, seja uma das maiores Constituições do planeta, pois, para compreendê-la, é necessário buscar a leitura que os tribunais fazem do seu texto. Integram a Constituição as decisões judiciais que dão densidade aos seus princípios diante do caso concreto ${ }^{11}$.

10 MIRANDA Jorge. Teoria do estado da constituição. 3. ed. rev., atual. e ampl. Rio de Janeiro: Forense, 2011. p. 247

11 MAGALHÃES, José Luiz Quadros de. O constitucionalismo norte-americano e sua contribuição para a compreensão contemporânea da Constituição. Jus Navigandi, Teresina, n. 452, out. 2004. Disponível em: $<$ http://jus.com.br/revista/texto/5769>. Acesso em: 18 dez. 2012. 


\section{CASO PLESSY V. FERGUSON}

A título ilustrativo convém referir que, nesse mesmo texto, o autor faz referência à pesquisa da Professora Carla Dumont Oliveira, da Pontifícia Universidade Católica de Minas Gerais, sobre a reforma da Constituição dos Estados Unidos, exemplificando o famoso caso Plessy $v$. Ferguson, no qual foi questionada uma lei de Louisiana, de 1890, que exigia acomodações iguais para brancos e negros, porém em partes separadas de um mesmo trem. A Suprema Corte entendeu que tal exigência era razoável e não feria a décima quarta emenda, pois o que visava a referida lei era promover o interesse público, a paz pública e a boa ordem, e não oprimir uma classe específica. Consta, ainda, da decisão, cujo Relator foi o Juiz Brown, que, se as duas raças buscam igualdade social, isso precisa ser o resultado do consentimento voluntário dos indivíduos, sendo que a legislação é impotente para erradicar instintos raciais. Plessy v. Fergunson iniciou a denominada doutrina dos "separados, mas iguais". Os precedentes Plessy $v$. Ferguson e Brown $v$. Board of Education foram retirados do livro The American Constitution: cases, comments, questions (p. 939-941) ${ }^{12}$.

Ainda acerca desse mesmo caso, a doutrina refere que a segregação em determinado período era legal nos Estados Unidos, relatando que o Juiz Brown, falando em nome do Tribunal, fundado na lei, rejeitou a alegação de que a separação forçada das duas raças marca a raça negra com estigma de inferioridade, e que, se isso acontecesse, não seria em virtude de qualquer coisa encontrada na lei, mas unicamente porque a raça negra resolveu interpretar desse modo ${ }^{13}$.

Conforme Bernard Schwartz, desde quando foi anunciada pela primeira vez, em 1954, a doutrina de Plessy v. Ferguson foi sistematicamente adotada pelo mais alto tribunal americano. Entretanto, diz o autor que a Suprema Corte, durante esse período não foi tão longe a ponto de reformar a decisão no caso Plessy, mas isso não significa, porém, que ela não tinha capacidade para tomar medidas importantes no sentido de melhorar a situação do negro dentro dos limites desse caso.

Enfim, naqueles tempos, a Suprema Corte sustentou e reconheceu a segregação, afirmando que ela seria válida somente se as acomodações destinadas aos negros fossem substancialmente iguais àquelas destinadas aos brancos ${ }^{14}$.

\section{A CORTE DE WARREN}

Fala-se, ainda, de uma revolução constitucional que teve início em 1954 com a nomeação de Earl Warren para a presidência da Suprema Corte norte-americana. Acerca da chamada revolução constitucional, faz-se oportuno

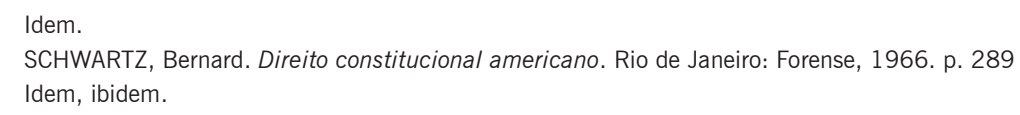


referir a manifestação do Professor Sérgio Moro, da Universidade Federal do Paraná, nos seguintes termos:

Nessa linha, é também imprescindível referência específica à célebre Corte de Warren, responsável por verdadeira revolução constitucional no período de 1953 a 1969. Sua influência ultrapassa as terras norte-americanas. O Direito Constitucional atual, e não somente nos Estados Unidos, mas em todos os países que adotam controle judicial de constitucionalidade, não pode ser compreendido sem referência à produção desta Corte. Para o bem ou para o mal, os termos dos debates constitucionais atuais foram estabelecidos por esta Corte. ${ }^{15}$

No que toca à segregação racial, somente com a Corte de Warren é que houve uma manifestação contrária a essa prática. Explica o Professor Sérgio Moro que no caso Brown v. Board Education, de 1954, é que foi declarada inconstitucional a segregação racial predominante nas escolas públicas no sul dos Estados Unidos, tendo a Corte, ainda, que enfrentar precedentes do caso Plessy $v$. Ferguson. Refere Sérgio Moro que Warren serviu-se de estudos psicológicos modernos para defender que a doutrina "separados, mas iguais", estabelecida em Plessy, não tinha lugar em matéria educacional, pois a simples segregação já comprometia o desenvolvimento educacional do grupo segregado, concluindo que a segregação era inerentemente desigual.

Ainda a respeito de questões referentes à proteção de direitos fundamentais, em seu artigo, o Professor Sérgio Moro aduz que,

no início do século, a Suprema Corte americana vivia a época conhecida como a Era Lochner, assim denominada pelo conhecido caso Lchner $v$. New York, de 1905, o qual invalidou lei do Estado de Nova York que estabelecia limite para a carga horária de trabalho dos empregados de padaria. Destacou-se, nesse período, por seu ativismo judicial conservador. Invalidou, sistematicamente, com base no princípio da razoabilidade e guiada pelo liberalismo econômico então predominante, as nascentes leis de intervenção do domínio econômico, inclusive, as que protegiam os trabalhadores.

A doutrina então aventada significava que a Corte passaria a adotar um duplo padrão no exame da constitucionalidade das leis. ${ }^{16}$

Em que pesem todas as discussões acerca da soberania, da democracia e da flexibilidade da Constituição norte-americana, parece que a questão da interpretação da Constituição pode dar azo a decisões que nem sempre respeitaram o Bill of Rigths, tão festejado pelos Fundadores da Constituição.

15 MORO, Sérgio Fernando. A corte exemplar: considerações sobre a Corte de Warren. Revista da Faculdade de Direito da UFPR, Curitiba, v. 36, 2001. p. 337.

16 Idem, ibidem. 
Diante dessas informações, fica a dúvida: essas possibilidades de divergentes interpretações seriam, de fato, a intenção dos idealizadores da Constituição dos Estados Unidos?

\section{DA DIVISÃO DE PODERES}

Analisando a situação política vivenciada na época da promulgação da Constituição norte-americana, não é difícil chegar à conclusão de que por meio dos pensamentos de Monstesquieu e Locke, acerca da doutrina da separação dos poderes, aliados ao temor da tirania do legislativo, é que a Constituição previu um modelo de separação de poderes em que o Poder Judiciário ficasse no mesmo nível político dos outros dois poderes, de modo a possibilitar uma limitação de força dos outros dois.

Montesquieu foi um dos pensadores que mais apoiou a separação de poderes em legislativo, executivo e judiciário. Sendo que, na divisão de poderes proposta por John Locke, o autor apontava a existência de quatro funções fundamentais do Estado: a legislativa, que cabia ao Parlamento; a executiva, que era exercida pelo Rei; a função federativa, que era uma extensão da função executiva para atividades fora do Estado; e, finalmente, a quarta função, que era o Rei fazer o bem à sociedade sem se subordinar a regras.

Não restam dúvidas de que os escritos de Montesquieu influenciaram consideravelmente a opinião dos idealizadores da Constituição dos Estados Unidos, mostrando uma divisão de poderes como a que conhecemos hoje.

Conforme já dito, a teoria da Separação de Poderes na forma que conhecemos hodiernamente somente surgiu no Século XVIII. Foi com a obra "O Espírito das Leis" que Montesquieu expressou com mais clareza um sistema de poder o qual conjugou funções diversas de governar, referindo um poder legislador (para criar leis), um poder para executar as ordens e tarefas de um governo, e um poder para julgar. Todos harmônicos e independentes entre si, inspirando, assim, a configuração das Constituições que nasceriam posteriormente a este posicionamento doutrinário.

É nesse mesmo sentido a célebre disposição contida no art. 16 da Declaração dos Direitos do Homem e do Cidadão, de 1789: "Toda sociedade na qual não esteja assegurada a garantia de direitos nem determinada a separação de poderes não possui Constituição".

Cumpre referir aqui as palavras de James Madison:

A acumulação de todos os poderes, legislativos, executivos e judiciais, nas mesmas mãos, sejam de um, de poucos ou de muitos, hereditárias, autonomeadas ou eletivas, pode-se dizer com exatidão que constitui a própria definição de tirania. ${ }^{17}$

17 GOLDWIN, Robert A.; SCHAMBRA, William A. Op. cit., p. 190. 
Desta forma, os elaboradores da Constituição estadunidense, com fundamento na concepção de Montesquieu, formaram o que se chamou de separação rígida de poderes.

Ao contrário da Inglaterra, onde se verificou a ascensão da soberania do Parlamento, os Estados Unidos aumentaram os Poderes do Judiciário evitando, dessa forma, a ditadura do legislativo ${ }^{18}$.

Dispõe a Constituição que o Poder Legislativo é atribuído ao Congresso, o qual é composto pelo Senado e pela Câmara de Representantes (Artigo I, Seção I), o Poder Executivo será exercido pelo Presidente dos Estados Unidos e pelo seu vice (Artigo II, Seção I), o Poder Judiciário se compõe de uma Suprema Corte e de tribunais inferiores que forem sendo estabelecidos por determinação do Congresso (Artigo III, Seção I) ${ }^{19}$.

Para os Estados Unidos da América, não é possível separar a Constituição da função exercitada pela Suprema Corte, na qual as decisões se firmam com mais desembaraço, menos rigidez e mais flexibilidade do que nas cortes inferiores.

Resulta claro, portanto, que os fatores efetivos do poder estão refletidos de forma expressa no texto constitucional.

A jurisprudência daquele país colaborou para a longevidade do texto constitucional, que certamente não teria sobrevivido às crises históricas da sociedade americana. Não resta dúvida no sentido de que em razão do caráter atualizador da Suprema Corte norte-americana é que foram evitadas as reformas constitucionais.

\section{SISTEMA DE CHECKS AND BALANCES}

Conforme Renè David,

a Constituição dos Estados Unidos foi interpretada, por princípio, com grande flexibilidade. Os juízes do Supremo Tribunal dos Estados Unidos, nesse aspecto, pelos seus métodos de interpretação, anteciparam em cem anos os métodos teleológicos enaltecidos na França por Josserand. A Constituição dos Estados Unidos, declarou o juiz Hughes, é o que dizem os juristas. Todo o desenvolvimento dos Estados Unidos, a distinção do direito federal e do direito dos Estados e a própria história dos Estados Unidos foram comandadas pela interpretação dada pelo Supremo Tribunal a certas fórmulas da Constituição dos Estados Unidos. ${ }^{20}$

18 ROCHA, José de Albuquerque. Estudos sobre o poder judiciário. São Paulo: Malheiros, 1995. p. 88.

19 ESTADOS UNIDOS. Constituição (1787). A constituição dos Estados Unidos da América. Disponível em: <http://www.braziliantranslated.com/euacon01.html>. Acesso em: 10 dez. 2011.

20 DAVID, René. Op. cit., p. 497. 
Nesse passo, não se pode deixar de referir o sistema de freios e contrapesos (checks and balances) importado da "Constituição" inglesa. Naquele sistema havia uma ação da Câmara dos Lordes para balancear ou equilibrar os projetos de leis advindos da Câmara dos Comuns, de modo a evitar que o povo viesse a ameaçar os privilégios da nobreza.

Em que pese a adoção do referido sistema checks and balances, mister observar, por oportuno, que o direito constitucional americano difere em muito do direito constitucional inglês, exemplo disso é o princípio do controle judiciário da constitucionalidade das leis, preponderante nos Estados Unidos, que jamais foi admitido na Inglaterra.

Nesse mesmo sentido manifestou-se Bernard Schwartz:

A doutrina da revisão judicial da constitucionalidade das leis, e não o simples fato de que a Constituição é um documento escrito, é que estabelece a enorme diferença entre os sistemas americano e inglês. A pedra fundamental da estrutura constitucional da Inglaterra é a doutrina da supremacia parlamentar.

O mesmo autor invoca Jennings, salientando que "o Parlamento tem o direito de fazer ou desfazer qualquer lei, e que a lei da Inglaterra não reconhece a qualquer pessoa ou entidade o direito de rejeitar ou anular a legislação do Parlamento" ${ }^{\prime 21}$.

Mais adiante, Schwartz refere que "não é a Corte Suprema sozinha, mas a Corte Suprema, apoiada pela força da opinião pública informada, que tem tornado o controle judicial da constitucionalidade um fator tão importante no funcionamento do sistema de Governo americano", uma vez que "a aceitação da Corte Suprema e de sua autoridade na esfera constitucional está atualmente tão arraigada na consciência americana quanto a aceitação da competência dos tribunais em questões de Direito Privado na Inglaterra".

Conclui, dizendo que

o apoio básico do Judiciário federal dos Estados Unidos não se encontra na sua posição constitucional, que, em vários aspectos, é inerentemente fraca em comparação com a do Legislativo e a do Executivo, mas na aceitação pela opinião pública do seu papel como guardião da Constituição americana. Num Governo democrático, representativo como o nosso, escreve um juiz americano, o poder do Judiciário depende grandemente de sua reputação quanto à sua independência, integridade e bom senso. ${ }^{22}$

O caso que inaugurou o sistema de freios e contrapesos (checks and balances) nos Estados Unidos foi o conhecido Marbury X Madson, quando o Juiz-em-chefe Marshal decidiu no sentido de que o Poder Judiciário tinha por

21 SCHWARTZ, Bernard. Op. cit., p. 23-24.

22 Idem. p. 184-186. 
missão declarar a inconstitucionalidade e tornar nulos os atos do Congresso quando não estivessem em acordo com a Constituição.

Assim, o Supremo Tribunal dos Estados Unidos estabeleceu a partir de 1803 o princípio do controle judiciário de constitucionalidade de leis, mesmo das federais.

De igual forma, pela doutrina do Judicial Review, embora não prevista na Constituição, o Poder Judiciário passa a controlar o abuso de poder dos outros ramos.

Conforme ensina Renè David, o Supremo Tribunal dos Estados Unidos não exerce o controle da constitucionalidade apenas sobre leis federais e estaduais, ele exerce controle também sobre a maneira como as diversas jurisdições concebem a "commom law". Assim, qualquer decisão judiciária pode ser anulada se for julgada contrária a uma regra prescrita pela Constituição.

Esse controle tem enorme importância, porque é o instrumento pelo qual se impõe às jurisdições e ao legislador o respeito a certos princípios fundamentais, assegurando, na medida necessária, a uniformidade do direito nos Estados Unidos. Considerando que a Constituição é a lei fundamental do país, pode parecer, conforme o entendimento da Escola de Direito Natural, o qual prevalecia em 1787, que a própria força da commom law deriva sua autoridade da Constituição. Ela é a expressão autorizada do contrato social que une os cidadãos e legitima as instituições, não visando diretamente a resolver os litígios, mas estabelecendo as regras gerais de organização e de conduta dos governantes e dos administradores ${ }^{23}$.

Nos Estados Unidos, a lei não tem sentido enquanto não for interpretada pelos tribunais, é muito raro ver acórdãos estatuírem, sem invocarem precedentes judiciários, pela simples aplicação de uma lei. Em razão disso, há uma forte preocupação acerca da uniformidade do direito americano. A proliferação de leis nos Estados Unidos apresenta um problema bem particular daquele país: teme-se que a uniformidade da common law seja posta em perigo pelo fato de leis diferentes poderem intervir nos diversos Estados para modificar-Ihe suas regras ou introduzir-Ihes complemento.

O perigo de que a legislação dos Estados Unidos venha destruir a uniformidade do direito americano não foi sentido no século XIX, quando o sentimento da independência dos Estados estava ainda desperto e as reformas afetavam mais o processo que a substância do direito. Tomou-se consciência disso somente no século XX. A fim de tentar-se evitar a destruição da uniformidade de leis dos Estados Unidos, dois mecanismos foram postos em prática concomitantemente, quais sejam (i) a adoção de leis modelos, uniformes, em certas matérias em que a prática reconhecia a necessidade de uma intervenção legislativa; 
e a (ii) o desenvolvimento do direito federal, esse segundo mecanismo consiste em fazer intervir o Congresso dos Estados Unidos, ou a administração federal em todas as matérias em que a uniformidade do direito é necessária.

As fórmulas gerais usadas pela Constituição dos Estados Unidos, tal como interpretadas pelo Supremo Tribunal, permitem essas intervenções em todos os casos em que elas se tornem necessárias. Uma considerável modificação foi efetuada no que diz respeito às respectivas competências do direito federal e do direito estadual, independentemente de qualquer modificação formal da Constituição nos últimos cinquenta anos. É por esse meio - estendendo os poderes das autoridades federais - que se dá, principalmente, satisfação à necessidade de uniformidade do direito quando essa necessidade se faz sentir nos Estados Unidos da América ${ }^{24}$.

\section{PODER REGULADOR}

Nesse passo, importa referir que os métodos de interpretação da Constituição levaram os Estados Unidos e a Inglaterra ao desenvolvimento de um (novo) direito administrativo, e, consequentemente, de uma grande variedade de repartições públicas, comissões, tribunais administrativos. Não se quis somente por meio deles aliviar os tribunais já estabelecidos; pretendeu-se, também, assegurar o funcionamento das novas leis, especialmente nos domínios econômico e social, excluindo os métodos comumente utilizados nos tribunais. Este desenvolvimento produziu-se tanto no plano do direito federal quanto no direito dos diferentes Estados, tomando, especialmente no plano federal, uma extensão considerável.

O poder regulamentador não era atributo, em teoria, nos Estados Unidos, do Poder Executivo. A doutrina considera que se desenvolveu na sociedade um quarto poder - Administrative Power - distinto dos três poderes tradicionais. Tal como o Poder Executivo, esse poder foi confiado ao Presidente dos Estados Unidos. Mas, diferentemente do Poder Executivo, era exercido em colaboração e sob o controle de certo número de grandes comissões instituídas pelo Congresso. A primeira dessas grandes comissões foi a Interstate Commerce Comission, instituída em 1887 para controlar as estradas de ferro e regular, de modo geral, os transportes interestaduais. As grandes comissões administrativas multiplicaram-se a partir de então. Destaca-se, especialmente, a Federal Trade Comission, a Securities and Exchange Comission e a National Labor Relations Board. Estes organismos federais permanentes estão habilitados a estabelecer regulamentos e resolver litígios. O direito americano não pode ser compreendido em múltiplos domínios sem se estudar a obra dessas comissões. O novo corpo de direito (Administrative Law) é de caráter meio administrativo, meio 
jurisdicional, como a antiga equity, mas é elaborado e administrado por organismos que funcionam sob o controle dos tribunais de justiça tradicionais ${ }^{25}$.

Essa questão será mais bem analisada adiante, eis que se trata de um assunto bastante difundido na doutrina constitucional moderna.

Ora, conforme antes referido, Renè David já aludia que a doutrina considera que se desenvolveu na sociedade um quarto poder, o Administrative Power, o qual é exercido em colaboração e sob o controle das grandes comissões instituídas pelo Congresso.

Como no sistema da common law, os juízes têm competência para decidir tanto questões judiciais como administrativas, cabendo sempre ao Poder Judiciário apresentar a decisão final também acerca de questões que tramitam nos Tribunais Administrativos dos Estado Unidos.

Como já visto, nos Estados Unidos a existência das agências reguladoras data de 1887, quando foi criada a primeira agência independente dos Estados Unidos (Interstate Commercial Commission) para regulamentar os serviços interestaduais de transporte ferroviário, mas foi somente nos anos de 1937 que as agências se proliferaram, durante o New Deal ${ }^{26}$.

\section{ADMINISTRATIVE PROCEDURE ACT(LEI DE PROCEDIMENTO ADMINISTRATIVO) E AS AGÊNCIAS REGULADORAS}

Em 1947 foi promulgada a Lei de Procedimento Administrativo (Administrative Procedure $A c t$ ), a qual estabeleceu dois tipos de procedimentos: normas gerais baixadas pelas agências (Rulemaking) e os atos individuais (Adjudications), sendo que os Tribunais poderiam julgar ilegais os atos das agências, caso estes não estivessem de acordo com a Lei de Procedimentos ${ }^{27}$.

O conceito de agência nos Estados Unidos tem sentido bem amplo. Conforme a Lei de Procedimento Administrativo, seria "qualquer autoridade do governo dos Estados Unidos, esteja ou não sujeita ao controle de outra agência, com exclusão do Congresso e dos Tribunais". No entendimento de Maria Sylvia Zanella Di Pietro, excluídos os três poderes do Estado, todas as demais autoridades públicas constituem agências.

Assim, pode-se afirmar que, nos Estados Unidos, falar em agência é o mesmo que falar em Administração Pública, mas se exclui do conceito a Presidência da República, ou seja, naquele país, toda a organização administrativa se resume em agências. Existem vários tipos de agências, sendo que a classificação mais antiga considerava duas modalidades: as agências reguladoras

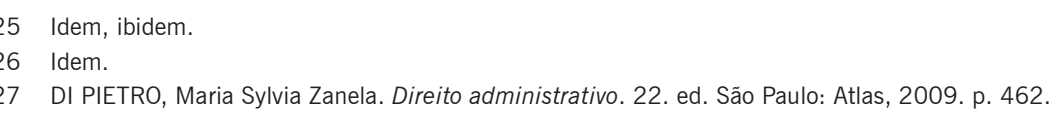


(regulatory agency) e as não reguladoras (non regulatory agency), conforme tivessem ou não poderes normativos, delegados pelo Congresso para baixar normas que afetassem os direitos, as liberdades ou atividades econômicas dos cidadãos.

Outra distinção que se faz é entre as agências executivas (executive agency) e agências independentes (independent regulatory agency or commissions), sendo os dirigentes das primeiras livremente destituídos pelo Presidente da República e, os da segunda, protegidos por maior estabilidade, porque só podem perder seus cargos por razões expressamente estabelecidas em lei ${ }^{28}$.

Nessa mesma senda, Lucia Valle Figueiredo explica que a justificativa para proibição do Presidente de destituir o pessoal das independent regulatory agency or commissions é que a cessão, a uma agência, de poderes quase legislativos e quase judiciais necessita da permanência de seus membros, que não poderia ficar na dependência presidencia ${ }^{29}$. Então, as agências norte-americanas exercem funções quase legislativas, porque editam normas; e funções quase judiciais, porque resolvem determinados conflitos de interesses, determinando o direito aplicável para solucioná-los. A função quase-judicial é aceita sem maiores complicações, uma vez que submetida ao controle pelos Tribunais. Sabe-se, entretanto, que tal função passou por toda essa evolução, no sentido de ampliar o controle.

A função quase legislativa tem sido objeto de grandes contestações, tendo em vista principalmente a ideia de indelegabilidade de poder, decorrente do princípio da separação de poderes, bastante rígido no direito norte-americano; esse princípio impede que o legislativo delegue a sua função de legislar a órgãos de outros Poderes.

Não se pode afirmar que os poderes reconhecidos às agências tenham sempre a mesma natureza e extensão. O tema passou por toda uma evolução, havendo uma fase de grande prestígio das agências e outra (atual) em que seus poderes vêm sendo grandemente limitados, especialmente o que diz respeito à sua função reguladora, devido à disputa entre Legislativo e Presidência da República em exercer o controle sobre as mesmas ${ }^{30}$.

\section{DISCUSSÃO ACERCA DA COMPETÊNCIA SOBRE AS AGÊNCIAS}

Lúcia Valle Figueiredo, mencionando Eloísa Carbonell, refere que a competência do Poder Executivo sobre as agências é apenas político, no sentido de que poderá coordenar as diferentes ações públicas com a política desenvolvida pelo Governo. Para ela, as agências podem ser criadas pelo Legislativo que thes

28 Idem

29 FIGUEIREDO, Lucia Valle. Curso de direito administrativo. 8. ed. rev. e ampl. São Paulo: Malheiros, 2006. p. 152.

30 DI PIETRO, Maria Sylvia Zanela. Op. cit., p. 463. 
entregará a fatia de poder que lhes entenda ser devida. Referindo, ainda, Eloísa Carbonell, aduz que esta é a primeira polêmica, porque se coloca o princípio da responsabilidade democrática, uma vez que ditas agências não teriam sido eleitas pelo povo, tal como o membros do Poder Legislativo; portanto, não sendo elas detentoras da delegação popular, seu poder regulador poderia ser discutido.

A delegação do Congresso americano passou por nítida evolução: inicialmente, entendeu-se que não poderia o Congresso delegar o que Ihe havia sido atribuído; depois, passou-se a aceitar, por forças das teorias contingented delegatio, named delegati e filling in details, a discricionariedade mínima do Executivo. Sendo ela o motivo principal da criação dessas agências pelos americanos, estava ligada à alta especialização nos vários campos de atuação do Executivo e ao entendimento de que, se houvesse possibilidade de gente especializada executar, melhor seria a prestação do serviço ou fiscalização.

A Suprema Corte inicialmente entendeu tais delegações inconstitucionais, porque o Congresso não havia assinado diretrizes ao Executivo nem exigira motivação das decisões. O Congresso pode e deve - e efetivamente utiliza sua competência - controlar a atividade administrativa. As agências são obrigadas, pois, a remeter ao Congresso todos os documentos que sejam necessários ao controle. Exatamente porque as agências, como autoridades executivas, dispunham de amplos poderes, foi criado o legislative veto (1932). Todavia, o problema das agências ainda se revelava delicado nessa época, porque, se de um lado havia a arguição de que poderes dados ao Congresso são dele, e, portanto, haveria inconstitucionalidade da delegação, de outra parte, a Corte Suprema entendia que o sistema do veto legislativo também atritaria com a separação de poderes - nessa última hipótese estaria havendo intromissão do Congresso, ou seja, do poder Legislativo no Executivo. Segundo a autora, nas últimas décadas produziu-se um progressivo aumento de interferência presidencial sobre as agências ${ }^{31}$.

Embora a Constituição norte-americana não refira nada acerca das agências reguladoras, cumpre mencionar que, no seu Artigo I, Seção 8, cláusula 18, dispõe acerca da competência do Congresso em editar leis necessárias e apropriadas ao exercício dos poderes que a Constituição confere ao Governo.

\section{DAS MODERNAS DOUTRINAS DA SEPARAÇ̃̃O DE PODERES}

\subsection{BRUCE ACKERMAN32}

Em que pese a adequação do sistema de divisão de poderes trazidos pela Constituição norte-americana, sabe-se que tal princípio modernamente vem so-

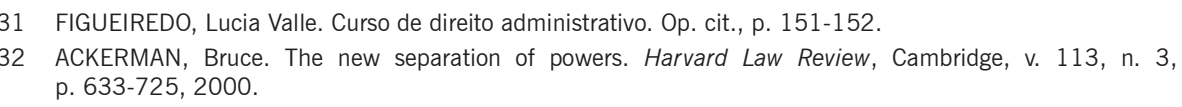


frendo algumas alterações, mormente no que se refere à questão das agências, ensejando, dessa forma, novas discussões e também uma possível releitura do mesmo.

Bruce Ackerman, constitucionalista norte-americano e professor de direito e ciência política da Law and Political Science, de Yale, autor de 15 livros, entre os quais se destacam The Decline and Fall of the American Republic (2010), The Failure of the Founding Fathers (2005) e do artigo intitulado The New Separation of Powers, apresenta uma nova leitura do princípio da divisão de poderes.

Ackerman inicia seu artigo afirmando que a mera exportação do sistema de divisão de poderes norte-americano não estaria correta, pois deixa de considerar as bem sucedidas experiências do parlamentarismo, mormente o que denominou de parlamentarismo pós-guerra, existentes em países como Japão e Alemanha. Refere que tais países adotaram o "constrained parliamentarism", ou parlamentarismo limitado, o qual teria origem no chamado "gabinete britânico", com alguns mecanismos de controle, de modo a diminuir a soberania parlamentar e a concentração de poder no seu órgão de cúpula.

No seu entendimento, o parlamentarismo limitado é uma força crescente no mundo e há muito o que ser aprendido com essa prática na última metade do século $X X$.

Da leitura de seu texto é possível observar claramente que Ackerman enfatiza pontos positivos do parlamentarismo, mostrando-se desfavorável ao regime presidencialista.

O autor faz várias críticas ao presidencialismo, asseverando que tal forma de governo traz um sistema político em torno de uma personalidade, sendo esse um grave defeito dentro do sistema. Ele considera que o sistema parlamentarista está menos sujeito a vicissitudes de uma personalidade, podendo, inclusive, haver um acordo multipartidário, fato que por si só já limitaria escândalos políticos, próprios do presidencialismo.

\subsubsection{Da crise de governabilidade observada por Ackerman}

Segundo ele, ainda, o atual sistema de separação de poderes tem o condão de ensejar uma crise de governabilidade, principalmente em razão do sistema presidencialista, uma vez que os órgãos legislativos e a presidência são ocupados por partidos políticos diferentes, o que certamente pode vir a causar divergências de posicionamentos, havendo, no seu entendimento, duas formas de governo no sistema presidencialista: (i) impasse (quando não se detém a maioria no Congresso) e (ii) autoridade plena (quando há a maioria no Congresso). 
Afirma que o Poder Legislativo pode deixar de desempenhar sua função primordial para, utilizando-se de instrumentos previstos no próprio ordenamento jurídico, intervir na atuação do Poder Executivo, que, por sua vez, poderá, para evitar uma crise maior, realizar ações unilaterais sempre que entender necessário. Enfim, ambas as formas de governo decorrentes do presidencialismo (impasse e autoridade plena) podem ser utilizadas de forma tirânica.

Para Ackermann, a nova separação de poderes procura evitar o impasse que pode surgir na crise de governabilidade.

A separação de poderes não envolveria tão somente a divisão entre Legislativo e Executivo, mas também a definição de qual a posição do Judiciário e das Agências Reguladoras dentro do sistema constitucional do país. Conforme seu entendimento, "é necessário que se defina de forma clara a função de cada um desses órgãos de modo a colaborar com a gestão do Estado".

\subsubsection{Da proposta de Ackerman}

Para Ackerman, são três os ideais de legitimação para responder a pergunta: "separar o poder em nome de que?". O primeiro ideal é democracia: de um modo ou de outro, a separação deve ser para servir ao projeto do autogoverno popular. O segundo ideal é competência profissional: as leis democráticas permanecem puramente simbólicas a menos que as Cortes e os órgãos administrativos possam as executar de uma maneira relativamente imparcial, elogia o profissionalismo no judiciário dos Estados Unidos, mas não no executivo. O terceiro ideal é a proteção e o realce dos direitos fundamentais: sem estes, as administrações democrática e profissional podem tornar-se motores da tirania.

Em suma, Ackerman refere em seu artigo a necessidade de uma nova doutrina de separação de poderes no Estado contemporâneo. Para tanto, sugere duas propostas: (i) criação de um poder responsável pelo controle da corrupção (integraty Brunch) e (ii) criação de um poder regulatório (regulatory Brunch).

\section{Integraty Brunch}

A corrupção não pode ser vista como um problema social, mas é certo que a burocracia não pode trabalhar se suas decisões ficam comprometidas, por exemplo, ao fato de uma de licitação de valor elevado intervir nas decisões administrativas. A construção digna de crédito de um poder responsável pela integridade deve ser uma prioridade máxima para os constituintes modernos.

\section{REgULATORY BRUNCH}

Verifica-se a necessidade da criação de agências reguladoras, tendo em vista que, embora a legislação democrática tenha os princípios de base, nem 
sempre os parlamentares têm a perícia e o conhecimento suficientes para elaborarem decisões com resultados efetivamente corretos.

Deve ser exigido um projeto constitucional que aceite a necessidade de órgãos reguladores no âmbito da Administração, pois se sabe que, muito embora seja antiga a existência das agências reguladoras, as questões pertinentes a elas são resolvidas em nível infraconstitucional, e, para os Estados Unidos, a efetividade de qualquer lei depende da sua apreciação pelo Supremo Tribunal. $\mathrm{O}$ argumento para a nova separação (funcional) de poderes pressupõe o valor do conhecimento científico e da experiência profissional no esforço regulador moderno.

\subsection{0 entendimento do Professor Neal Kumar Katryal ${ }^{33}$}

Nesse passo, cumpre aduzir, ainda, que no The Yale Journal, Neal Kumar Katyal, professor de Direito da Georgetown University Law School, publicou um artigo muito interessante a respeito desse mesmo assunto, questionando como a separação de poderes pode ser refletida dentro do Poder Executivo quando esse ramo está fazendo muito mais leis hoje em dia. O Professor Katyal lamenta o que ele vê como o desaparecimento da função de checagem do Congresso. De acordo com Katyal, o colapso da doutrina da não delegação e do veto legislativo, bem como o desejo dos tribunais de transferir para o Poder Executivo as relações exteriores deixaram o Congresso com "escassez de armas que fiscalizassem o Presidente".

\subsubsection{Das modificações propostas pelo Professor Katyal}

Para compensar o que considera como a abdicação do Congresso, da sua função, o Professor Katyal propõe uma série de reformas estruturais dentro do poder executivo. Refere que um mecanismo crítico para promover a separação de poderes interna é burocracia, a qual criaria um serviço civil (agências) sem criar obrigações com nenhuma administração particular, e criaria a longo prazo peritos com uma visão institucional de mundo. Seu artigo propõe um mecanismo que pode criar checks and balances dentro do Poder Executivo, na área dos negócios internacionais.

Os instrumentos seriam a separação e a sobreposição de jurisdição de agências, a consulta inter-agência, a revisão imperativa da ação governamental pelas diferentes agências, maior profissionalização do serviço civil, exigências de relatórios ao congresso, o estabelecimento de um diretor de julgamento independente para resolver as disputas inter-agências e a indicação de um mediador de agências.

33 KATYAL, Neal Kumar. Internal separation of powers: checking today's most dangerous branch from within. The Yale Law Journal, New Haven, v. 115, p. 2314-2349, 2006. Disponível em: <http://www.yalelawjournal.org/ pdf/115-9/Katyal.pdf >. Acesso em: 10 dez. 2011. 
Ou seja, sugere reformas dentro do Poder Executivo sem violar o compromisso da Constituição relativo ao Executivo Unitário. Em seu ensaio, Katyal refere que os ataques de 11 de setembro deram ao Congresso e ao Presidente uma oportunidade de trabalharem juntos, mas essa oportunidade não foi aproveitada.

Para ele, há muito o que falar acerca de violação de poderes em razão das decisões executivas decorrentes de 11 de setembro, mas o Congresso dos Estados Unidos não se manifestou a respeito. Por outro lado, ele comemora o potencial da burocracia (agências), explicando como essas instituições legais podem aumentar os seus poderes. Diz ele que a burocracia deve ser reformada e comemorada ao invés de ser removida e caluniada, e mecanismos neutros para solução de conflitos podem ser introduzidos; que escolhas de projetos como este podem ajudar a trazer de volta ao governo as linhas dos princípios previstos pelos Fundadores da Constituição norte-americana.

Conclui seu ensaio afirmando que a "América" tem duas escolhas, ou aceitar um Poder Executivo extremamente poderoso e os riscos decorrentes da reação (positiva ou negativa) do Tribunal, ou trazer de volta a tradicional divisão de poderes que até então serviu tão bem ao país. Cabe aos americanos descobrirem como traduzir a ideia da divisão de poderes dentro de uma modernidade em que Presidentes devem agir rapidamente para evitar calamidades.

Para o Professor Katyal, os tribunais, evidentemente, têm conhecimento de que existe a tendência de um Poder Executivo mais forte nos tempo de crise. Em consequência, pode-se esperar que, em razão de o Executivo se tornar mais monolítico, os tribunais funcionem tão somente como uma espécie de verificação, mas que também tal verificação judicial poderá falhar. Aos tribunais, falta perícia em muitas áreas e podem intervir quando não devam e refrear a intervenção quando deveriam intervir. Por este motivo (e outros), devem ser feitas escolhas de projetos institucionais de forma a permitir que funcionem, simultaneamente, uma fonte de legitimidade do Executivo e também a vontade democrática e perícia.

Afirma, ainda, que responsabilidade política é um princípio central do Executivo Unitário, mas absolutamente não justifica o expansivo poder presidencial implantado em segredo e pareceres jurídicos designados a permanecer em segredo. Para ele, o pêndulo hoje começa a balançar tão forte em direção ao vigor do Poder Executivo que o que se deve temer é que os princípios do governo dividido, idealizado pelos fundadores, já não funcionem mais. Refere, finalmente, o Professor Katyal, que, dando força às tradições que já são parte do obscuro cenário constitucional, a superposição burocrática, proteção de serviços civis, adjudicação interna, exigência de relatórios são alguns movimentos que podem direcionar ao retorno do equilíbrio. 


\subsection{Pode o diálogo entre agências SerVIr como a nova separação de poderes? (Professor Christopher S. Yoo $)^{34}$}

\subsubsection{Resposta ao Professor Katyal}

De outro lado, em alguns pontos concordando com o Professor Katyal e em outros pontos o contrariando, o Professor Christopher S. Yoo, da University of Pennsylvania Law School, publicou, em resposta, no mesmo The Yale Journal, um artigo chamado "Can Interagency Dialogue Serve as the New Separation of Powers?", no qual refere que recomendou ao Professor Katyal que assumisse o princípio da separação de poderes ao invés de condená-lo como uma obstrução ou como um pretexto para engrandecimento presidencial (observe-se, como já visto, que Katyal sugeriu uma reforma no Poder Executivo sem, contudo, violar o compromisso da Constituição relativamente ao Executivo Unitário, criticando o aumento do Poder Executivo).

Assevera o Professor Yoo que o Congresso moderno já tem desenvolvido novas ferramentas para restringir o aumento do Poder Executivo. No mínimo, desde os anos 70, o Congresso cada vez mais tem confiado nos controles menos formais no comportamento da agência, conduzindo mais audiências e investigações de supervisão, decretando dotações, adendos e outras cláusulas administrativas, detalhando como os funcionários do executivo deveriam administrar a lei, inclusive a linguagem em discursos e relatórios de comitês para influenciar o comportamento da agência, escrevendo para as autoridades das agências sobre a resolução de casos em particular, e tirando concessões durante as audiências de confirmação de administradores. Sendo que o uso destas práticas permanece difundido mesmo durante períodos de governo de partido único.

Sugere que o Professor Katyal observe a importância de tais instrumentos quando ele faz sua série de exigências.

Refere também que o Congresso já começou a empregar o tipo de consultas multiagência proposto pelo Professor Katyal. Por exemplo, a Lei das Telecomunicações, de 1996, requer que a Comissão Federal de Telecomunicações consulte um Procurador-Geral antes de permitir que uma antiga empresa de telefonia regional venda serviços a longa distância em determinadas regiões. Os estatutos com relação a drogas, da mesma forma, exigem que o Procurador-Geral busque a opinião do Secretário de Saúde e Serviços Sociais antes de adicionar uma droga à lista do governo federal de substâncias controladas. No mesmo artigo, o Professor Yoo provoca o debate afirmando que a principal solução do Professor Katyal para a incapacidade percebida do Congresso de supervisionar o poder Executivo é a burocracia, e que, a seus olhos, os burocratas são mais do

34 Yoo, Christopher S. Can interagency dialogue serve as the new separation of powers? The Yale Law Journal Pocket Part, New Haven, v. 116, p. 131-136, 2006. Disponível em: <http://yalelawjournal.org/images/ pdfs/72.pdf >. Acesso em: $10 \mathrm{dez} .2011$. 
que apenas fornecedores da burocracia, são repositórios da expertise e a personificação do "profissionalismo ligado à tradição"; que os burocratas estruturam decisões em uma perspectiva de mais longo prazo que transcende as exigências políticas transitórias.

\subsubsection{Burocracia segundo Marver e Niskanen}

Esta, conclui ele, é apenas uma das muitas visões de burocracia, e as conclusões que se tira das consequências de dar poder à burocracia dependem fortemente da teoria que se defende. Segundo o Professor Yoo, deve ser considerado, em primeiro lugar, o trabalho seminal de Marver Bernstein, que caracteriza as agências como passando por um ciclo de vida. Durante seus estágios iniciais, uma agência persegue o interesse público; com o decorrer do tempo, a agência perde a vitalidade e se torna cada vez mais alinhada à indústria que está encarregada de regularizar - um resultado também prognosticado pela "teoria da captura". Sobre este ponto de vista, se a consulta inter-agência promovesse o expertise e uma perspectiva de mais longo prazo, dependeria do estágio de ciclo de vida de cada agência envolvida na decisão.

Refere, ainda, que William Niskanen afirma que os burocratas podem ser mais bem compreendidos enquanto construtores de império que tentam maximizar seus orçamentos. O resultado é a superprodução sistemática de serviços governamentais, com funcionários do alto escalão do Executivo tentando tornarem-se advogados para os programas que eles representam e resistentes ao controle presidencial. Curiosamente, Niskanen propõe a concorrência entre agências, não apenas para consultoria, mas para a prestação de serviços ao governo. Os benefícios resultam não da expertise ou de uma perspectiva a mais longo prazo, mas, ao invés, da disciplina fornecida pela concorrência por financiamento, o que Niskanen considerou como muito mais eficaz do que a supervisão presidencial em restringir o comportamento de agências.

\subsubsection{Burocracia segundo Lessig e Sunstein}

Refere que o papel determinante desempenhado pela teoria particular da burocracia, usada para analisar o problema, é mais claramente ilustrado ao se comparar a proposta do Professor Katyal com uma oferecida por Lawrence Lessig e Cass Sunstein. Embora Lessig e Sustein compartilhem a crença do Professor Katyal de que o setor executivo exerce agora maior poder sobre o fazer política, eles rejeitam a fé progressiva de Katyal na expertise burocrática, que consideram desacreditada e um tanto bizarra, em prol da opinião que os julgamentos administrativos são inerentemente políticos. Como resultado, eles acreditam que o crescente envolvimento da burocracia federal no fazer política justifica o fortalecimento do controle presidencial sobre os departamentos executivos.

Embora, o Professor Yoo não concorde com toda a análise de Lessig e Sunstein, considera surpreendente que as diferenças na teoria básica de buro- 
cracia os façam chegar a conclusões que divergem fortemente das do Professor Katyal, muito embora eles partam de um ponto inicial semelhante.

\subsubsection{Congresso e a Presidência}

Conclui seu artigo aduzindo que algumas das posições assumidas pela Administração atual fazem com que o crescimento do Poder Executivo se torne um problema novo e perigoso. Na realidade, entretanto, o equilíbrio do poder executivo-legislativo tem fluxo e refluxo ao longo do tempo. A forte presidência de Abraham Lincoln foi precedida e seguida por períodos de dominação legislativa. Igualmente, Watergate gerou um período de Congresso forte - durante os quais muitas inovações nas quais o Professor Katyal confia -, tais como conselhos e inspetores gerais independentes, alcançaram seu apogeu - que, por sua vez, foi seguido por um retorno à ascendência presidencial com Ronald Reagan. E, mesmo durante períodos de governo de partido único, tais como as administrações de Franklin Roosevelt, Kennedy, Johnson e Carter, bem como partes das Administrações de Truman e Eisenhower, membros do Congresso influenciaram agências administrativas e se distanciaram das ações executivas não populares. Por isso, a História sugere que a política, e não a estrutura institucional, explica melhor as trocas no poder entre o Congresso e o Presidente.

Segundo ele, o próprio Professor Katyal parece reconhecer, no mínimo implicitamente, esta lição da história quando ele observa que, mesmo se o Congresso tivesse que criar um Diretor de Adjudicação para inspecionar as reivindicações de agências rivais, o Presidente, contudo, permaneceria livre para desconsiderar os resultados. Afirma que, na análise final, Katyal reconhece que as soluções estruturais apenas podem fazer uma parte, mas que as proteções básicas contra o poder presidencial são políticas e não legais.

\subsection{LAURENCE TRIBE ${ }^{35}$}

Finalmente, importa referir o posicionamento de Laurence Tribe acerca da separação de poderes no que diz respeito às agências nos Estados Unidos.

Para Tribe, a separação de poderes comanda e permeia o Direito Constitucional norte-americano. A separação de poderes forma não somente os tópicos que implicam estrutura governamental ou a atribuição de poder (tais como os poderes de verificação dos tribunais federais, ou delegações, por parte do Congresso de autoridade aos organismos administrativos), mas também forma questões que se pressupõem incentivadas pela substância e pela estrutura constitucional (tais como os valores de justiça incorporados no processo legislativo). O princípio da separação de poderes tem efeitos penetrantes porque envolve a própria estrutura do governo; para ele nada está mais perto do núcleo do direito 
do que o sistema de divisão de poderes (poderes divididos mas interligados), que estão incorporados na estrutura do nosso governo.

A doutrina da separação de poderes, que evoluiu nos últimos 200 anos, tem menos da filosofia política do que da experiência prática. Noções modernas da separação de poderes não podem ser facilmente destiladas a partir das inclinações filosóficas dos fundadores. Qualquer que seja a força normativa, aquelas intenções podem manter uma interpretação constitucional até os dias de hoje. Tanto os fundadores como os homens que participaram da primeira administração sob a nova Constituição (que muitas vezes eram as mesmas pessoas) estavam preocupados mais com melhorar a eficiência e a capacidade do governo nacional do que com a criação de um sistema de governo baseado nas máximas abstratas de filósofos políticos. Embora a separação de poderes desempenhe um papel de moldar as opiniões daqueles que forjaram o governo nascente, as opiniões expressadas não eram doutrinárias - em parte porque não havia doutrina clara. Embora possa ser algo exagerado, é mais ou menos verdade que a ideia de separação de poderes dos fundadores era sem forma e experimental, e que eles tinham alguns arranjos institucionais fixos em mente, além do princípio básico que deveria ser a separação.

Em muitos casos, a ideia de separação de poderes foi usada como uma arma retórica, com fins de exaustão política dos adversários ou até mesmo para legitimar as próprias preferências constitucionais, ao invés de um guia claro para a construção de um governo seguro e eficaz.

Devemos, portanto, buscar um entendimento da separação de poderes da Constituição, não principalmente no que os fundadores pensaram, nem em que os filósofos políticos do lluminismo escreveram, mas no que a própria Constituição diz e faz. O que conta não é qualquer teoria abstrata de separações de poderes, mas a separação real de poderes "operacionalmente" definida pela Constituição. Portanto, onde o texto constitucional é informativo em relação a uma separação de poderes, é importante não pular esse trecho em favor de princípios abstratos para vê-los incorporados no nosso regime de poderes separados.

O autor recomenda cautela ao se trazer princípios abstratos para fundamentar a interpretação do texto constitucional.

A ascensão do estado administrativo e das agências independentes, como a Securities and Exchange Commission e a Federal Reserve Board apresenta um desafio em relação ao plano de governo da Constituição. Provavelmente, o fato de que tais agências (apesar de serem uma novidade em relação à visibilidade dos fundadores) devam operar dentro dos limites estabelecidos pelo Congresso e devam ser executadas pelo Poder Judiciário Federal impede que elas representem um verdadeiro "quarto Poder" de governo, portanto, violando a Constituição, embora se vislumbre a suposta necessidade de existência de tais agências. É útil contrastar a delegação de poder para essas agências com as tentativas do 
Congresso de delegar poderes a si mesmo, ou a uma de suas casas ou comissão, ou outro organismo no seu âmbito, ou sujeitos ao seu controle.

Tal delegação introvertida, normalmente desenvolvida para atrelar o Congresso a uma agência para quem ele delega amplos poderes, inicialmente, poderia não fazer sentido prático em termos de dinâmica política da situação, mas certamente parece mudar radicalmente o desenho, ou estrutura do diagrama de poder da Constituição, confiando ao legislador nacional um papel direto na aplicação, ou execução, da sua própria lei.

A decisão da Suprema Corte no caso INS v. Chadha, que invalidou o chamado veto legislativo, não foi particularmente persuasiva, mas qualquer outro resultado teria sido extremamente difícil de conciliar com o plano constitucional. Embora fosse possível apoiar a decisão invocando a proibição textual contra os membros do Congresso atuarem como oficiais dos Estados Unidos, a razão mais forte para a inconstitucionalidade do veto legislativo é a diferença fundamental entre um projeto constitucional, em que o legislador nacional é deliberadamente separado do ramo acusado de executar as leis, e um sistema essencialmente parlamentar, no qual o governo é escolhido a partir da legislatura e em nenhum sentido separado dela. Mais uma vez, a base constitucional para o julgamento torna-se, no fundo, uma organização e, portanto, característica invariante da política norte-americana.

Quanto ao enraizamento das agências em nosso panorama social e econômico por meio de um corpo enorme de direitos e uma variedade igualmente grande de prática, o ponto importante ao final é que o estatuto constitucional deve ser medido não em termos de texto somente, mas dentro da história e estrutura da Constituição, bem como as considerações da doutrina constitucional e precedentes.

\section{CONCLUSÃO}

No tocante à longevidade da Constituição norte-americana, ficou demonstrado que a interpretação jurisprudencial no sistema norte-americano alterou-se de tal forma ao longo desses mais de 200 anos que deu origem a decisões diametralmente opostas, mas que, no entanto, foram que baseadas no mesmo texto constitucional. Exemplos de mudança de interpretação não faltam ao longo da história jurídica dos Estados Unidos, seja no que diz com direitos fundamentais, sociais e econômicos, e políticos. Verificou-se, nesse passo, que a denominada Corte de Warren deixou sua marca por meio das drásticas mudanças de interpretação que as decisões daquela Corte legaram ao Direito norte-americano.

A partir daí, verifica-se que mudanças ocorreram no direito constitucional americano, sem, contudo, haver mudança no texto legal. Conforme bem referiu José Luiz Quadros de Magalhães, o principal motivo da existência de 
poucas mudanças formais do texto constitucional por meio de emendas é que o referido texto é sintético e principiológico, permitindo, dessa forma, mutações interpretativas e mudança de compreensão do seu sentido, o que tornaria desnecessário o recurso de constante mudança de texto, pois se muda a Constituição mudando-se apenas o seu sentido, sua compreensão, sem mudar-se o texto. Exemplo disso também se verifica que os métodos de interpretação levam os Estados Unidos ao desenvolvimento de um direito administrativo, conforme ensina Renè David.

Conclui-se, ainda, que os modernos constitucionalistas americanos são favoráveis a uma nova divisão de poderes, sendo que Ackerman sugere duas propostas à criação de um poder responsável pelo controle da corrupção e a criação de um poder regulatório (criação de agências reguladoras). Para Katyal, está havendo um aumento de poder do Executivo, sendo que o Congresso padece do que ele chama de "escassez de armas que fiscalizem o Presidente". Teme Katyal que, pelo fato de o Executivo tornar-se ainda mais forte, os tribunais funcionem tão somente como uma espécie de verificação, sendo que essa verificação pode vir falhar, pois, segundo ele, falta aos tribunais perícia em muitas áreas e, em razão disso, sugere reformas dentro do poder executivo sem violar o compromisso da Constituição relativo ao Executivo Unitário. Sugere, assim, a criação de um serviço civil (agências) sem criar obrigações com nenhuma administração particular, que criaria peritos com uma visão institucional a longo prazo.

Já Christopher S. Yoo refere que o Congresso moderno já tem desenvolvido novas ferramentas para restringir o aumento do poder executivo, discordando, com Katyal, acerca da necessidade de criação de agências, mas concorda no sentido de que algumas posições assumidas pela Administração atual fazem com que o crescimento do Poder Executivo se torne um problema novo e perigoso.

Para Tribe, a separação de poderes comanda e permeia o Direito Constitucional norte-americano, conforme o seu entendimento o que conta não é qualquer teoria abstrata de separação de poderes, mas a separação real de poderes operacionalmente definida pela constituição.

Assevera que a ascensão do estado administrativo e das agências independentes apresenta um desafio em relação ao plano de governo da Constituição, e que tais agências (apesar de serem uma novidade em relação à visibilidade dos fundadores) devem operar dentro dos limites estabelecidos pelo Congresso e devem ser executadas pelo Poder Judiciário Federal, impedindo-se, assim, que elas representem um verdadeiro "quarto Poder". Recomenda, desta forma, cautela ao se trazer princípios abstratos para fundamentar a interpretação do texto constitucional.

O presente artigo, portanto, trouxe a lume uma questão realmente nova para o direito atual, qual seja a hipótese de uma possível alteração no sistema 
de divisão de poderes da Constituição estadunidense, noticiando entendimentos divergentes de alguns doutrinadores modernos.

\section{REFERÊNCIAS}

ACKERMAN, Bruce. The new separation of powers. Harvard Law Review, Cambridge, v. 113, n. 3, 2000.

DAVID, Renè. Os grandes sistemas de direito contemporâneo. São Paulo: Martins Fontes, 2002.

DI PIETRO, Maria Sylvia Zanela. Direito administrativo. 22. ed. São Paulo: Atlas, 2009. FIGUEIREDO, Lucia Valle. Curso de direito administrativo. 8. ed. rev. e ampl. São Paulo: Malheiros, 2006.

GOLDWIN, Robert A; SCHAMBRA, William A. Constituição norte-americana. Rio de Janeiro: Forense, 1986.

KATYAL, Neal Kumar. Internal separation of powers: checking today's most dangerous branch from within. The Yale Law Journal, New Haven, v. 115, 2006.

MAGALHÃES, José Luiz Quadros de. O constitucionalismo norte-americano e sua contribuição para a compreensão contemporânea da Constituição. Jus Navigandi, Teresina, n. 452, out. 2004. Disponível em: <http://jus.com.br/revista/texto/5769>. Acesso em: 18 dez. 2012.

MIRANDA Jorge. Teoria do estado da constituição. 3. ed. rev., atual. e ampl. Rio de Janeiro: Forense, 2011.

MORO, Sérgio Fernando. A corte exemplar: considerações sobre a Corte de Warren. Revista da Faculdade de Direito da UFPR, Curitiba, v. 36, 2001.

ROCHA, José de Albuquerque. Estudos sobre o poder judiciário. São Paulo: Malheiros, 1995.

SCHWARTZ, Bernard. Direito constitucional americano. Rio de Janeiro: Forense, 1966. TRIBE, Laurence H. American constitutional law. New York: Foundation Press, 2000.

YOO, Christopher S. Can interagency dialogue serve as the new separation of powers? The Yale Law Journal Pocket Part. Disponível em: <http://thepocketpart.org/2006/11/2/yoo. html>. 